Pak. j. sci. ind. res. Ser. B: biol. sci. 2021 64B(3) 244-250

\title{
Phytochemical, Antioxidant and Antimicrobial Activity of Biological Important Algae Hydrodictyon reticulatum L.
}

\author{
Mehwish Jaffer ${ }^{\mathrm{a}}$, Hammad Ashraf ${ }^{\mathrm{b}}$ and Shabnum Shaheen ${ }^{\mathrm{a}^{*}}$ \\ ${ }^{a}$ Department of Plant Taxonomy, Lahore College for Women University, Lahore-54000, Pakistan \\ bPlant Phycology Lab., Government College of Science, Wahdat Road, Lahore-54000, Pakistan
}

(received August 29, 2018; revised March 19, 2019; accepted April 8, 2019)

\begin{abstract}
The recent research was directed to explore the phytochemical, antimicrobial and antioxidant activity of Hydrodictyon reticulatum L. The samples were then identified morphologically and anatomically. By using different solvents algal extracts were prepared. The phytochemical activity of algal samples were performed to determine the presence or absence of alkaloids, steroids, tannin, triterpenoids, saponin, terpenoids, quinine, coumarins, phlobatannins, phytosteroids and flavonoids. Two bacterial strains $S$. aureus and $E$. coli were used to determine the antibacterial activity of algal extracts. The greatest activity was appeared by the methanolic extract against the fungal strain $S$. aureus i.e. $12.5 \pm 0.088 \mathrm{~mm}$, while the aqueous extract showed the maximum anti-bacterial activity that was $12.2 \pm 0.058 \mathrm{~mm}$ beside $E$. coli. These findings were relatively equivalent to the results of standard Amkasin that was normally used as antibiotic in the market. The results of antifungal movement was indicated greatest having the solvent $\left(\mathrm{CH}_{3}\right)_{2} \mathrm{CO}$ separate i.e. $1.8 \pm 0.058 \mathrm{~mm}$ against $A$. niger. While methanol extricate indicated $2.35 \pm 0.058 \mathrm{~mm}$ against the strain F. solani. DPPH rummaging activity, TAA and TPC were performed to determine the action of H. reticulatum. In the event of DPPH the most extreme IC50 recorded was from the chloroform extricate. While in TPC methanol extricate indicated most extreme esteem $67.14 \pm 0.54 \mathrm{~mm}$ and in TAA ethanol showed greatest esteem i.e. $0.88 \pm 0.01 \mu \mathrm{g} / \mathrm{L}$. These results demonstrated that the Hydrodictyon reticulatum had phytochemical, cancer prevention agent and antimicrobial potential and suggested for pharmaceutical use.
\end{abstract}

Keywords: Hydrodictyon reticulatum, phytochemical, antibacterial, DPPH, antifungal, total phenolic content

\section{Introduction}

Aquatic organisms are an amusing source of anatomically original and naturally dynamic metabolites. Many microscopic forms of algae are known to grow in fresh water as slimy 'blanket weed'. One such familiar algae is Spirogyra, filamentous algae, its cells form every filament comprises of widespread chain of like cells. Spirogyra is the best communal genus of Zygnemataceae and member of the algae found in fresh water. It displays the highest variety of the 12 to 13 genera documented in green algae family (Kadlubowska et al., 1978; Transeau, 1951).

Un-controlled generation of responsive oxygen species (ROS) including hydroxyl radical $\left(\mathrm{OH}^{-}\right)$, superoxide radical $\left(\mathrm{O}^{-2}\right)$, hydrogen peroxide $\left(\mathrm{H}_{2} \mathrm{O}_{2}\right)$, hydroperoxyl radical $\left(\mathrm{H}_{2} \mathrm{O}_{2}\right)$, lipid peroxyl radical $\left(\mathrm{LOO}^{-}\right)$, alkoxyl radical $\left(\mathrm{LO}^{-}\right)$and singlet oxygen $\left(\mathrm{O}_{2}\right)$ has been ensnared in different sicknesses, for example, malignancy, atherosclerosis, diabetes mellitus, interminable

\footnotetext{
*Author for correspondence;

E-mail: shabnum_shaheen78@hotmail.com
}

aggravation and in addition neurodegenerative infections, for example, alzheimer, parkinson and maturing (Duan et al., 2006). Moreover, ROS can advance lipid oxidation that antagonistically influences the surface, shading and kind of nourishment items, bringing about release of wonderful volume of sustenance and monetary misfortune (Min and Ahn, 2005).

Because of the expanding purchaser mentality for characteristic mixes, consideration has been moved towards common additives especially from plant sources (Cakir et al., 2003). In this respects, numerous novel cell reinforcements have just been disconnected from different sorts of plants, herbs and flavours (Shon et al., 2003). Characteristic cancer prevention agents are not constrained to earthly plant and some marine green growth were accounted for to have cell reinforcement action (Demirel et al., 2009; Chew et al., 2008; Duan et al., 2006).

A wide range of substance and engineered mixes are utilized as antimicrobial operators to restrain the development of pathogenic micro-organism, yet they 
can cause an assortment of negative symptoms too (Rabiey et al., 2013) mixes got from regular sources, for example, marine green growth can be utilized as sheltered antimicrobial specialists (Dashtiannasab et al., 2012).

Hydrodictyon reticulatum $\mathrm{L}$. A dense network or net like Chlorophyte alga. This mesh up of net intermingled and attain the shape of sac like system, that's why commonly named as water net with respect for fast growth. It is generally basic sideways lakes, lakes and waterways and so on with sack or layer like settlements (Flory and Graham, 2007).

Antimicrobial is a general term including all administrators that exhibit against an extensive variety of micro-organisms, for instance, organisms (antibacterial), contaminations (antiviral), developments (antifungal) and protozoa (antiprotozoal). A particle, which forestalls oxidation, called as cell reinforcement. It was contemplated already that oxidative pressure has numerous effects and could prompt increment of numerous sicknesses like atherosclerosis, alcoholic liver cirrhosis, growth and so on (Ramarathnam et al., 1995).

\section{Material and Methods}

Sample collection. Algal samples were mainly collected in the plastic bags from different areas of Lahore. The areas for sample collection were canal road, BRB road, Ravi road and Iqbal park.

Green growth tests were cleaned all epiphytes and necrotic parts were evacuated. All the collected samples were washed with sterile water to evacuate any unwanted dirt or soil particles. The samples were then dried using filter paper sheets and then the samples were shade dried so that all the moisture were removed. After drying of algal samples the samples were ground to fine powder using pestle and mortar. The powdered samples were then soaked in different solvents: ethanol, methanol, chloroform and water. The extraction was carried out for 10 days, after that extracts were filtered, the filtrate is dried using rot evapourator and concentration was determined and subjected to analysis (Goud et al., 2007).

Sample identification. The sample collected were identified using the standard literature of Prescott (2007) and Shamilian system of classification, 2015.

Hydrodictyon reticulatum. Classification. Plantae + , Viridiplantae + , Chlorophyta + , Chlorophyta + ,
Chlorophytina+, Chlorophyceae+, Sphaeropleales + , Hydrodictyaceae+, Hydrodictyon Roth, 1797+.

Hydrodictyon reticulatum (Linnaeus) Bory. Characteristics. Hydrodictyon reticulatum also known as water net. The cells of this alga tied so tightly with cells that it form a mesh or network of long filaments. The filament is $50 \mathrm{~cm}$ long networks unmistakably obvious in extensive provinces. Cells are round and hollow to elliptical oval, up to $15 \mathrm{~mm}$ long 2-4 neighbouring cells associated by their edges and framing 5-6-sided networks as appeared in (Fig. 1).

Sample preparation. The algal extract for further studies were prepared by using methodology stated by Vlachos et al. (2001). For this the powdered of algal samples were dipped in $150 \mathrm{~mL}$ methanol, ethanol, acetone, chloroform and water for $24 \mathrm{~h}$ utilizing a Sox Let Extraction Device. The solvents were vanished and the subsequent concentrates were kept at $\pm 4{ }^{\circ} \mathrm{C}$.

Phytochemical estimation. The concentrates were subjected to phytochemical tests for estimation of subsequent phytochemical active compounds by utilizing the standard subjective techniques as depicted in writing (Gosh et al., 2010).

Test for glycosides. $10 \mathrm{~mL}$ of $50 \% \mathrm{H}_{2} \mathrm{SO}_{4}$ was added to the $1 \mathrm{~mL}$ of concentrate in a test tube. The blend was warmed in boiling water shower for $5 \mathrm{~min} .10 \mathrm{~mL}$ of Fehling's answer ( $5 \mathrm{~mL}$ of every arrangement A and B) was included and bubbled. A block red accelerate showed the nearness of glycosides.

Examination for alkaloids. In to the $3 \mathrm{~mL}$ of concentrate $1 \mathrm{~mL}$ of $1 \% \mathrm{HCl}$ was added in a test tube and was
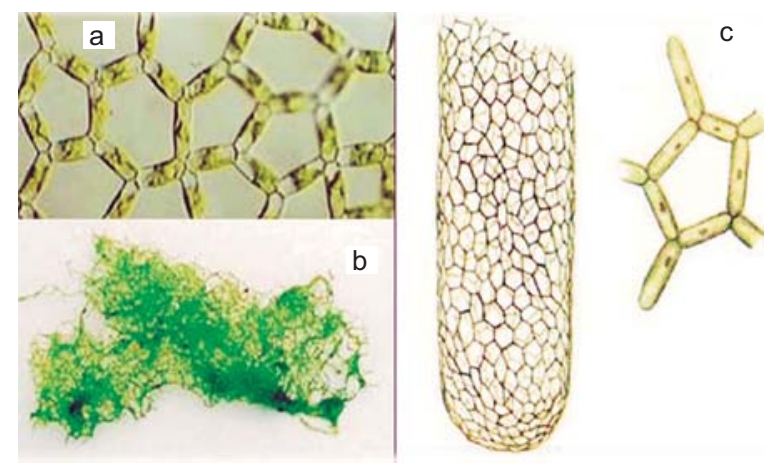

Fig. 1. The investigated algal species: (a) Microscopic view of Hydrodictyon reticulatum (b) Collected algal sample (c) Coenobium. 
treated with few drops of Meyer's reagent. A velvety white hasten showed the nearness of alkaloids.

Examination for saponins. Took $5 \mathrm{~mL}$ of concentrate in a test tube and was shaken overwhelmingly to get a stable determined foam. The foaming was then blended with 3 drops of olive oil and watched for the development of emulsion, which demonstrated the nearness of saponins.

Test for flavonoids. Few drops of $1 \% \mathrm{NH}_{3}$ solution was added in a test tube having $2 \mathrm{~mL}$ of the algal extracts. The yellow shading was watched for the nearness of flavonoids.

Test for tannins. For this $0.5 \mathrm{~mL}$ of extracts were taken in test tubes and in these test tubes $1 \mathrm{~mL}$ of water along with 1-2 drops $\mathrm{FeCl}_{3}$ was added in these tubes. The green red ring formation indicated the presence of tannins in the sample.

Test for terpenoids. $5 \mathrm{~mL}$ of algal extracts was blended with $2 \mathrm{~mL}$ of $\mathrm{CHCl}_{3}$ in a test tube. $3 \mathrm{~mL}$ of concentrated $\mathrm{H}_{2} \mathrm{SO}_{4}$ was deliberately included along the sides the test tube to shape a layer. An interface with a ruddy dark coloured tinge was affirmed the nearness of terpenoids.

Test for cardiac glycosides. $5 \mathrm{~mL}$ of algal extract was blended with $2 \mathrm{~mL}$ of frigid acidic corrosive containing 1 drop of $\mathrm{FeCl}_{3}$. The above blend was deliberately added to the $1 \mathrm{~mL}$ of concentrated $\mathrm{H}_{2} \mathrm{SO}_{4}$. Immediacy of heart glycosides was distinguished by the arrangement of a darker ring.

Test for phlobatannins. $10 \mathrm{~mL}$ of concentrate was added with $1 \% \mathrm{HCl}$ in a glass test tube. Affirmation of a red precipitates demonstrated the nearness of phlobatannins.

Test for anthraquinones. Extract was blended well with benzene and after that half of its own volume of $10 \%$ smelling salts arrangement was included. Nearness of a pink, red or violet tinge in the smelling salts stage demonstrated the anthraquinones.

Test for phenols. $3 \mathrm{~mL}$ of $10 \%$ lead acetic acid were added to $5 \mathrm{~mL}$ of algal extracts. The appearance of white precipitates indicated the presence of phenols.

Valuation of antimicrobial activity. The approximation of antibacterial activity was performed on nutrient broth and nutrient agar that were used as medium for improvement of bacterial settlement according to the (Cruickshank, 1975) methodology. For this the potato dextrose medium (PDA) was used as medium for the evaluation of antibacterial activity using protocol given by (Pierre et al., 2011) and agar-well dispersal methodology was grasped that was given by (Costa et al., 2010).

Valuation of antioxidant activity. DPPH radical scavenging activity. DPPH radical searching planned was examined by utilizing approach utilized by (Lee and Shibamoto, 2001). The absorbance was recorded utilizing spectrophotometer at the wavelength of 517 $\mathrm{nm}$. BHT was utilized as standard. The $\%$ staining of the DPPH was computed by utilizing the accompanying recipe

Percentage discolouration $=\left[1-\left(\mathrm{A}_{\text {sample }} / \mathrm{A}_{\text {control }}\right) \times 100\right]$

TAA by Phospho molybdenum method. The antioxidant inhibition agent capability of the algal concentrates was done by the technique given by (Prieto et al., 1999). The Absorbance was checked by utilizing the UVspectrophotometer at absorbance of $695 \mathrm{~nm}$, gallic acid (GA) utilized as standard.

Evaluation of aggregate phenolic substance. TPC test was done by utilizing the approach connected by (Makkar et al., 1993). The absorbance was ascertained by utilizing spectrophotometer at $725 \mathrm{~nm}$ wavelength. BHT act as a standard.

Statistical analysis. All information, communicated as mean SD, were measurably broke down by SPSS programming (adaptation 16.0, SPSS Inc., Chicago, IL, USA), utilizing one-path investigation of difference (ANOVA). Ordinariness was tried by KolmogorovSmirnov Test and homogeneity of differences checked by Levee's test.

\section{Results and Discussion}

Phytochemical analysis. Imperative phytochemicals, for example, tannin, alkaloids, steroids, triterpenoids, saponin, coumarins, quinine, terpenoids, phlobatannins, phytosteroids and flavonoids were screened for their quality and introduced in Table 1 . These results indicated the presence of many important phytochemical compounds and it was also observed that different solvents show different results. Acetone proved out to be the best solvent, whereas water showed the least solubility of compounds.

Antimicrobial activity. The antimicrobial activity was examined using five different solvents given in 
Table 1. Phytochemical studies of the algal specimen using different solvents

\begin{tabular}{llllll}
\hline \hline Sr. No. & Methanol & Ethanol & Acetone & Chloroform & Water \\
\hline Glycosides & - & - & - & - & - \\
Alkaloids & - & - & - & - & - \\
Saponins & ++ & ++ & ++ & - & - \\
flavonoid & - & - & ++ & - & - \\
Tannins & - & - & ++ & - & - \\
terpenoids & ++ & - & ++ & + & - \\
cardiac & ++ & ++ & ++ & + & + \\
glycosides & & & & & - \\
phlobatannins & - & - & - & - & - \\
Anthraquinone & - & - & - & - & - \\
Phenols & ++ & ++ & ++ & - & - \\
\hline \hline
\end{tabular}

++ Copiously present, + moderately present, - absent

(Fig. 2, 3). Among all the solvents used, the maximum zone of hindrance was appeared by methanol extract against $E$. coli i.e. $2.2 \pm 0.058 \mathrm{~nm}$, while least zone of hindrance was communicated by $\left(\mathrm{CH}_{3}\right)_{2} \mathrm{CO}$ that was $1.9 \pm 0.058 \mathrm{~nm}$. If there should arise an occurrence of $S$. aureus, greatest action was shown by $\left(\mathrm{CH}_{3}\right)_{2} \mathrm{CO}$ separate $(2.5 \pm 0.088 \mathrm{~nm})$. Yet, in water no movement was displayed by both $S$. aureus and E. coli., while leading antifungal activity the outcome were clear as Aspergillus niger demonstrated most extreme action in $\left(\mathrm{CH}_{3}\right)_{2} \mathrm{CO}$ that was up to $1.8 \pm 0.058 \mathrm{~nm}$. Minimum movement $(1.4 \pm 0.033 \mathrm{~nm})$ was consider in both methanol and ethanol. If there should be an occurrence of Fusarium solani, most extreme action was shown by both methanol and water was $2.3 \pm 0.058 \mathrm{~nm}$, while least zone was appeared by ethanol that was $1.7 \pm 0.058 \mathrm{~nm}$. These outcomes indicated that the result was almost equal to the standard antibacterial and antifungal used in the

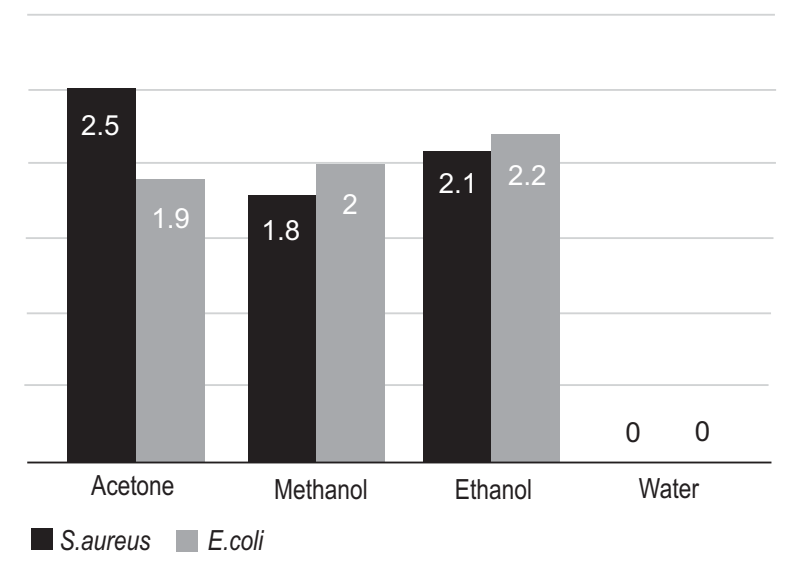

Fig. 2. Zone of inhibition $(\mathrm{cm})$ of bacterial strains against algal extracts. market and standard (Fig. 4, 5). (Ambreen et al., 2012) examined higher antibacterial action in the dark coloured green growth than the green and red green growth, yet (Vallinayagam et al., 2009) discovered higher degrees of antibacterial movement in the concentrates from the red green growth. The contrast between the consequences of the present examination and those of different investigations might be because of the algal species, natural solvents utilized, geographic region, periods of the year, temperature of the water and the antibacterial test strategies (Dashtiannasab et al., 2012). The antibacterial action of the algal concentrates might be because of the nearness of amino acids, terpenoids, phlorotannins, steroids, phenolic mixes, halogenated ketones and alkanes, cyclic polysulphides, unsaturated fats and acrylic corrosive and also lipophilic, lipid dissolvable phenol segments and colors, for example, $\beta$-carotene. Contingent upon the particular mixes removed by every dissolvable, it appears that changed concentrates even from a similar alga can indicate different exercises against the particular bacterium. Along these lines, one might say that distinctive microorganisms can indicate different degrees of affectability when treated with these concentrates. By and large, gram positive microbes, for example, L. monocytogenes and $B$. subtilis are touchier to algal concentrates than gram negative micro-organisms, for example, E. coli (Bhagavathy et al., 2011).

Antioxidant activity. In TPC highest activity was observed in methanol extract given in (Fig. 6a and b) i.e. $67.14 \pm 0.54$ that was higher than standard $63.09 \pm 1.2$ and least activity was measured by water that was

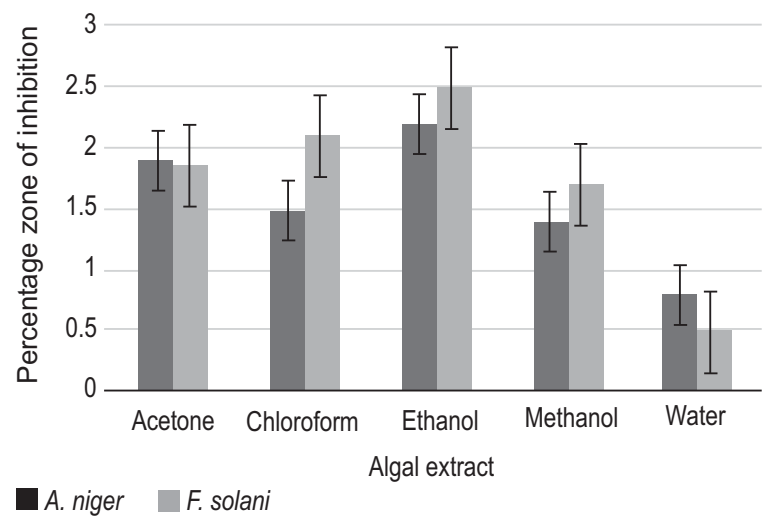

Fig. 3. Zone of inhibition $(\mathrm{cm})$ of fungal strains against algal extracts. 


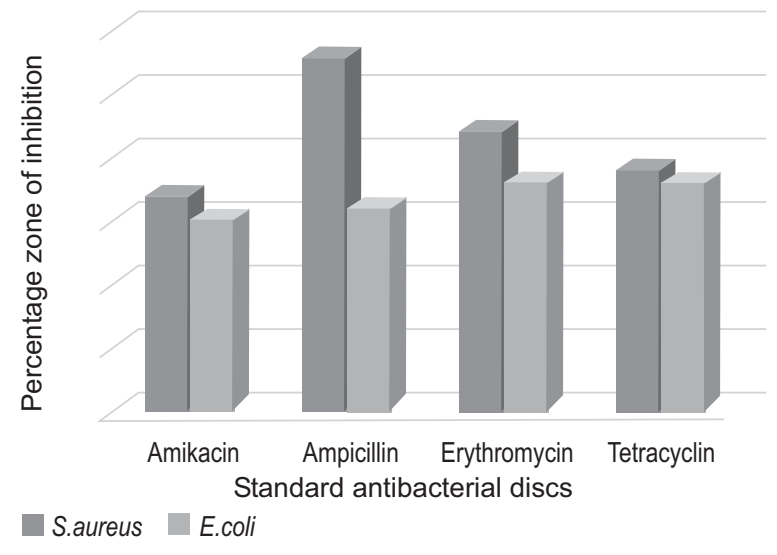

Fig. 4. Zone of inhibition ( $\mathrm{mm}$ ) produced by the bacterial strains against standard antibiotic discs.

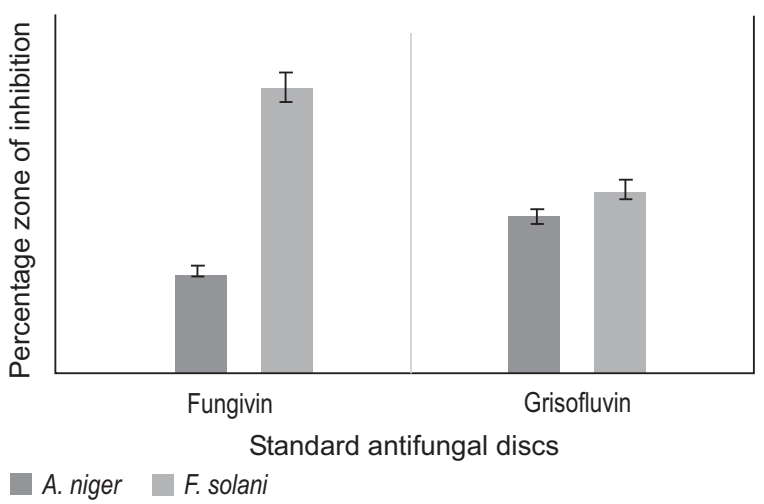

Fig. 5. Zone of inhibition (mm) of fungal strains against the standard antifungal discs.

$12 \pm 0.020$. In TAA activity, the maximum value was up to $0.88 \pm 0.01$ by ethanol extract that is higher than the maximum value of standard gallic acid as shown in (Fig. 7a and b).

DPPH method mainly examined to investigate the potential of antioxidant compounds to deed as free radical scavengers. It depends on the decrease of the steady, purple-shaded radical DPPH into the yellowhued DPPH (Shon et al., 2003). In case of DPPH, maximum $\mathrm{IC}_{50}$ value was displayed by chloroform extract that was up to 45.98 which was much greater than the standard 12.17 (Fig. 8). These outcomes indicated that the algae that were still give no such importance actually contain such bioactive compounds that were appeared to be equally important to those compounds that were extracted from plants.

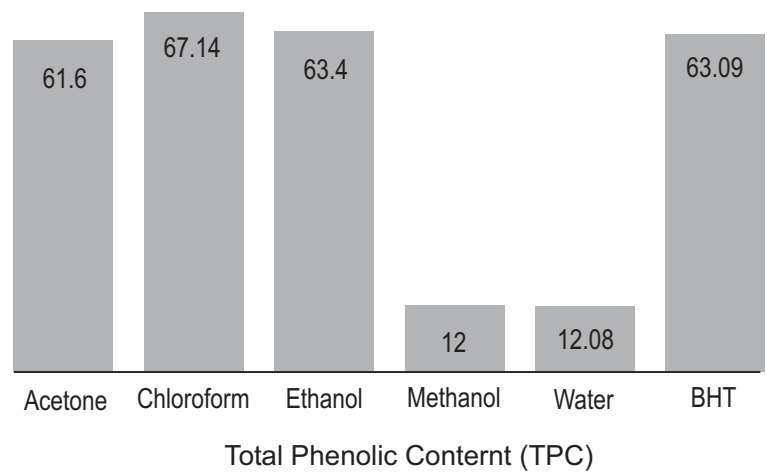

Fig. 6a. Absorbance of algal extracts by total phenolic content.

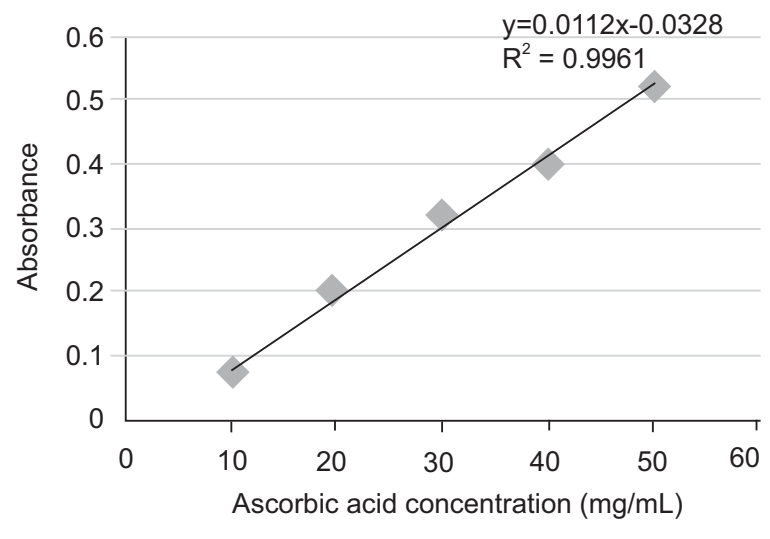

Fig. 6b. Standard curve for TPC (total phenol content (mg TAE g-1)).

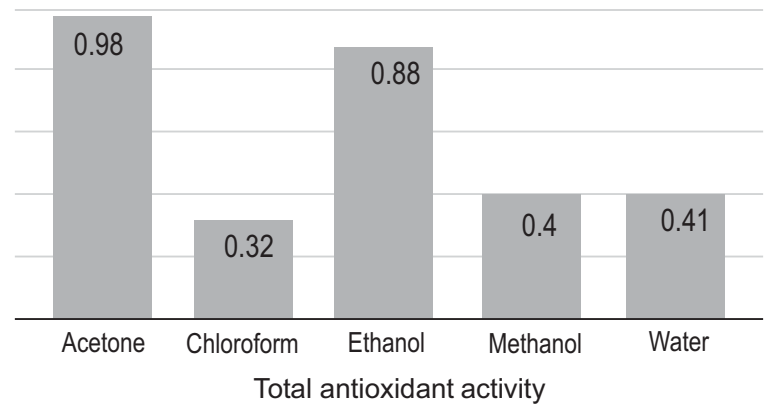

Fig. 7a. Absorbance of algal extracts by total antioxidant activity.

Past examinations have discovered remarkable fluctuations in the synthetic elements with alteration of seasons and natural situations (Manivannan et al., 2009). 


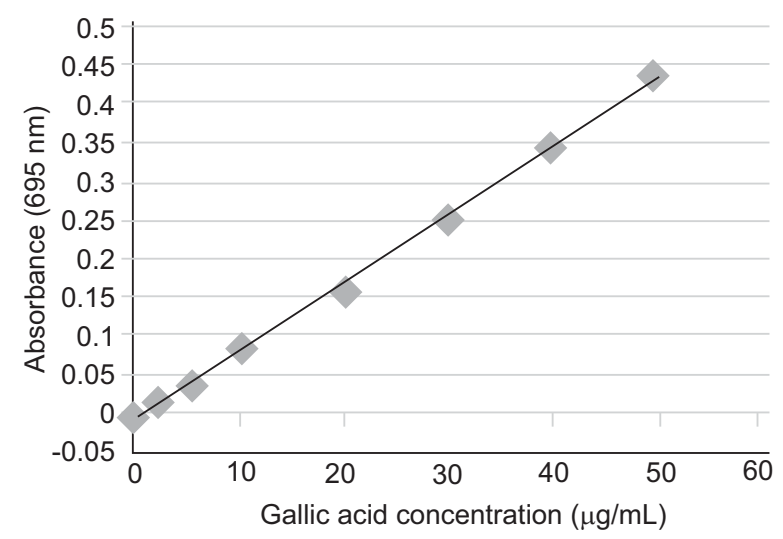

Fig. 7b. Standard curve for TAA (total antioxidant activity).

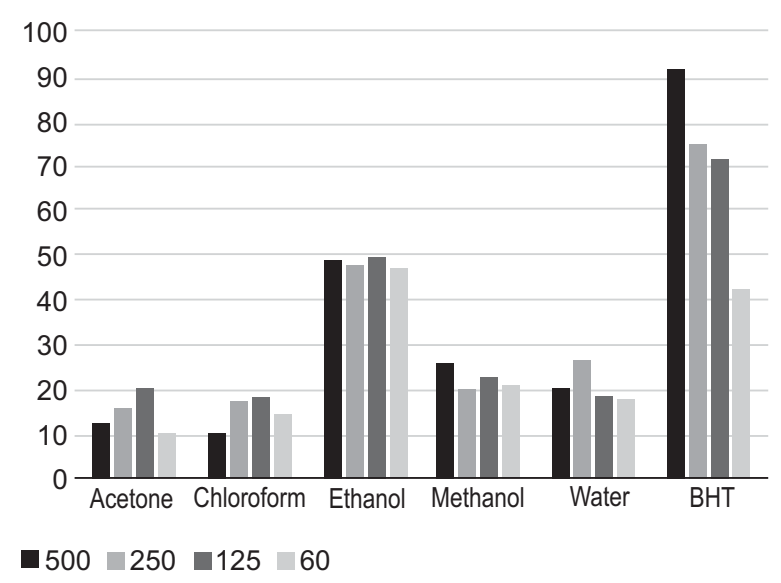

Fig. 8. Absorbance of algal extract by DPPH.

The creation of ROS particularly happens under the conditions amid presentation to over the top light, or UV radiation and additionally amid drying up, under supplement lack, introduction to overwhelming metals, low or high temperatures and fluctuation in temperature (Dummermuth et al., 2003). It was mainly watched that, creation of ROS in marine green filamentous algae was fortified mainly by different natural anxieties, for example, high light levels, overwhelming metals, UV radiation, high salt focuses and so forth. Green growth for the most part have higher cancer prevention agent movement because of higher substance of nonenzymatic cell reinforcement segments, for example, ascorbic corrosive, diminished glutathione, phenols and flavonoids (Wu et al., 2010).

\section{Conclusion}

The current research indicate the existence of phytochemical, antioxidant and antimicrobial activity of the fresh water algae Hydrodictylon reticulatum. Which indicated that not only plants were of pharmacological importance, algae were also proved equally important same as plant. So, by using the easily available source algae we can attain better results as the outcomes were correlated with the antibacterial and antioxidant compounds used regularly in market and we can easily protect the green cover of the land.

\section{Abbreviations}

$\mathrm{TPC}=$ Total phenolic content; TAA $=$ Total antioxidant activity; DPPH=2,2-diphenyl-1-picrylhydrazyl; $S$. aureus $=$ Staphylococcus aureus; E. coli=Escherichia coli; B. subtilis=Bacillus subtilis; L. monocyto genes $=$ Listeria monocytogenes .

\section{Acknowledgement}

We are really gratefull to Government College of Science Lahore for providing the help and assessment in research conduction.

Conflict of Interest. The authors declare no conflict of interest.

\section{References}

Ambreen, A., Hira, K., Ruqqia, A., Sultana, V., Ara, J. 2012. Evaluation of biochemical component and antimicrobial activity of some seaweeds occurring at Karachi coast. Pakistan Journal of Botany, 44: 1799-1803.

Bhagavathy, S., Sumathi, P., Sherene, B. 2011. Green algae Chlorococcum humicola- a new source of bioactive compounds with antimicrobial activity. Asian Pacific Journal of Tropical Biomedicine, (S1-S7): 127-129.

Cakir, A., Mavi, A., Yildirim, A., Duru, M.E., Harmandar, M., Kazaz, C. 2003. Isolation and characterization of antioxidant phenolic compounds from the aerial parts of Hypericum hyssopifolium L. by activity-guided fractionation. Journal of Ethnopharmacology, 87: 73-83.

Chew, Y., Lim, Y., Omar, M., Khoo, K. 2008. Antioxidant activity of three edible seaweeds from two areas in south east Asia. LWT- Food Science and Technology, 41: 1067-1072. 
Costa, L.S., Fidelis, G.P., Cordeiro, S.L., Oliveira, R.M., Sabry, D.A., Câmara, R.B.G. 2010. Biological activities of sulfated polysaccharides from tropical seaweeds. Biomedicine and Pharmacotherapy, 64: 21-28.

Crui.ckshank, R., Duguid, J.P., Marmion, B.R., Swain, R.H.A. 1975. Medical Microbiology, 12th Ed., pp. 812-825, Living stone, London, New York, USA.

Dashtiannasab, A., Kakoolak, S., Sharif, M.R., Yeganeh, V. 2012. In vitro effects of Sargassum latifolium (Agardeh, 1948) against selected bacterial pathogens of shrimp. Iranian Journal of Fisheries Science, 11: 765-775.

Demirel, Z., Ferda, F., Yilmaz-Koz, N.U., Karabay, Y., Ozdemir, G., Sukatar, A.A. 2009. Antimicrobial and antioxidant activity of brown algae from the Aegean sea. Journal of the Serbian Chemical Society, 74: 619-628.

Duan, X.J., Zhang, W.W., Li, X.M., Wang, B.G. 2006. Evaluation of antioxidant property of extract and fractions obtained from a red alga, Polysiphonia urceolata. Food Chemistry, 95: 37-43.

Dummermuth, A.L., Karsten, U., Fisch, K.M., Konig, G.M., Wiencke, C. 2003. Responses of marine macroalgae to hydrogen-peroxide stress. Journal of Experimental Marine Biology and Ecology, 289: 103-121.

Flory, J.E., Graham, R.W.H. 2007. A Hydrodictyon reticulatum bloom at Loe Pool. European Journal of Phycology, 29: 17-20.

Goud, M.J.P., Seshikala, D., Charya, M.A.S. 2007. Antibacterial activity and biomolecular composition of certain fresh water microalgae from river Godavari (India). Science World Journal, 2: 19-23.

Kadlubowska, J.Z. 1978. Chlorophyta V. conjugales, Zygnemaceae, Zrostnicowate. Krakow, Polska Akademia Nauck, pp. 1-431.

Lee, K.G., Shibamoto, T. 2001. Antioxidant property of aroma extract isolated from clove buds (Syzygium aromaticum (L.) Merr. Et Perry). Food Chemistry, 74: 443-448.

Makkar, H.P.S., Blummel, M., Borowy, N.K., Becker, K. 1993. Gravimetric determination of tannins and their correlations with chemical and protein precipitation methods. Journal of the Science of Food and Agriculture, 61: 161-165.

Manivannan, K., Thirumaran, G., Karthikai, D.G.,
Anantharaman, P., Balasubramanian, T. 2009. Proximate composition of different group of seaweeds from Vedalai coastal waters (Gulf of Mannar), Southest coast of India. Middle East Journal of Scientific Research, 4: 72-77.

Min, B., Ahn, D. 2005. Mechanism of lipid peroxidation in meat and meat products, A review. Food Science and Biotechnology, 14: 152-63.

Pierre, G., Sopena, V., Juin, C., Mastouri, A., Graber, M., Maugard, T. 2011. Antibacterial activity of sulfated galactan extracted from the marine alga Chaetomorpha aerea against Staphylococcus aureus. Biotechnology and Bioprocess Engineering, 16: 937-945.

Prieto, P., Pineda, M., Aguilar, M. 1999. Spectrophotometric quantitation of antioxidant capacity through the formation of a phosphomolybdenum complex: Specific application to the determination of vitamin E. Analytical Biochemistry, 269: 337-41.

Rabiey, S., Hosseini, H., Rezaei, M. 2013. The hurdle effect of Bunium persicum essential oil, smoke and $\mathrm{NaCl}$ for controlling the Listeria monocytogenes growth in fish model systems. The Journal of Food Safety, 33: 137-144.

Ramarathnam, N., Osawa, T., Ochi, H., Kawakish, S. 1995. The contribution of plant food antioxidants to human health. Trends in Food Science and Technology, 6: 75-82.

Shon, M., Kim, T., Sung, N. 2003. Antioxidants and free radical scavenging activity of Phellinus baumii (Phellinus of Hymenochaetaceae) extracts. Food Chemistry, 82: 593-597.

Transeau, E.N. 1951. The Zygnemataceae (Fresh-Water Conjugate Algae) with Keys for the Identification of Genera and Species and Seven Hundred EightyNine Illustrations, pp. 1-327, 789, The Ohio State University Press, Columbus, USA.

Vallinayagam, K., Arumugam, R., Kannan, R., Thirumaran, G., Anantharaman, P. 2009. Antibacterial activity of some selected seaweeds from pudumadam coastal regions. Global Journal of Pharmacology, 3: 50-52.

Wu, S.C., Wang, F.J., Pan, C.L. 2010. The comparison of antioxidative properties of seaweed oligosaccharides fermented by two lactic acid bacteria. The Journal of Marine Science and Technology, 18: 537-545. 